\title{
Glute Exercise and Basic Exercise Therapy Improve Ankle Stability in Patients With a Chronic Ankle Sprains
}

\author{
Donal Syafrianto $^{1 *}$, I Nyoman Mangku Karmaya ${ }^{2}$, and Syahmirza Indra Lesmana ${ }^{3}$ \\ ${ }^{I}$ Dep. of Health and Recreation, Faculty of Sport Science, Padang State University, Padang, Indonesia \\ ${ }^{2}$ Dep. of Anatomy, Faculty of Medicine, Udayana University, Bali, Indonesia \\ ${ }^{3}$ Dep. of Physical Therapy, Faculty of Physical Therapy, Esa Unggul University, Jakarta, Indonesia \\ "Corresponding author. Email: donalsyafrian@fik.unp.ac.id
}

\begin{abstract}
Chronic ankle sprain causes ankle instability, which is accompanied by a decreased reaction of gluteus muscle strength due to changes in muscle activation and proprioceptive disorders. The purpose of this study is to prove whether the addition of glute exercise to basic exercise therapy further increases ankle stability in cases of chronic ankle sprain. he research method in this research is experimental with pre-test and post-test control group design. In this study, 9 respondents were given the addition of glute exercise to basic exercise therapy for 8 weeks of exercise frequency 2 times a week. Hypothesis test results indicate the addition of glute exercise in basic exercise therapy can significantly improve ankle stability, before treatment $24.22 \pm 4.024$ and after treatment with a value of $8.89 \pm 2.147$ with a value of $\mathrm{p}=0.000(\mathrm{p}<0.05)$. The conclusion of this study is the addition of glute exercise to basic exercise therapy to further improve ankle stability in patients with a chronic ankle sprain.
\end{abstract}

Keywords: Ankle instability, chronic ankle sprain, glute exercise, basic exercise therapy

\section{INTRODUCTION}

Sport is a form of planned and structured physical activity that involves repetitive body movements and is intended to improve physical fitness. Sports are some of the basic needs in human life because they can improve the fitness needed for doing everyday tasks. Sports activities aimed at health, pleasure and sports achievement.

Every doing physical activity, especially sports, the perpetrators are always faced with the risk of injury, as a result of injuries will interfere with physical activity, psychological and achievement.

Sports injuries result in pain, loss of play or work time, and require medical care. There are several factors that cause injury, including errors in training methods, structural abnormalities, muscle weakness and joint support.[1]

One of the injuries that occur in sports is an ankle sprain or ankle sprain, ankle sprain is an ankle injury because of sudden movements that are lateral or medial which results in torn ligamentous fibers in the ankle joints.

About $85 \%$ of ankle sprain occurs due to inversion injury, this injury occurs due to the number of stabilizing bones on the outside or side which causes the pressure on the foot to be reversed. The ankle joint is prone to injury because it is unable to resist medial, lateral, pressure and rotation strength.[2]
Chronic ankle sprain is very influential on the occurrence of ankle stability disorders, this can be seen from the incidence of sequelae and the development of chronic ankle instability after lateral ankle sprain occurs around $31 \%$ to $40 \%$. When ankle sprain occurs, damage does not only occur to the structure of ligament integrity but also to various mechanoreceptors around the ankle. Collectively, these receptors provide feedback on joint pressure and tension, which will ultimately provide information about movement and position of joint.[3]

Two theories that cause ankle instability in general are mechanical instability and functional instability.[4] Mechanical instability refers to the measurement of ligamentous weakness, whereas functional instability comes from a neuromuscular system deficit.[5]

The weakness of the lower extremity muscles is caused by a disruption of the sensorimotor system which is a complex integration of afferent and efferent information. Efferent output provides global stabilization through postural and local stability through joint functional stabilization.[6]

In this study, researchers wanted to find out more about the effect of decreased ankle stability and decreased gluteus muscle strength after chronic ankle sprain. To help complaints arising from cases of ankle sprain such as 
impaired ankle stability, physiotherapy interventions to be used are basic exercise therapy and glute exercise.

The formulation of the problem in this study are: Does the addition of glute exercise to basic exercise therapy further improve the stability of the ankle with chronic ankle sprain sufferers?

This study aims: To prove the addition of glute exercise in basic exercise therapy further improves ankle stability in patients with chronic ankle sprain.

This research is expected to be useful as an insight to increase ankle stability in cases of chronic ankle sprain by providing strength training in ankle muscles by providing basic exercise therapy interventions, as well as giving glute exercise in helping to improve ankle stability.

\section{MATERIALS AND METHODS}

A. Research Scope

The study was conducted at Poltekkes Dr. Rusdi Medan for 8 weeks from March to April 2016. This research involved the futsal team player Karya Setia and the Poltekkes futsal team Dr. Rusdi Medan who suffered a chronic ankle sprain injury. This study uses experimental methods with pre-test and post-test design. Addition of glute exercise to basic exercise therapy. Research was conducted to prove the increase in ankle stability by administering both methods of exercise. The ankle stability value is measured using a balance eror scorring system (BESS).

\section{B. Population and Samples}

The sample population in this study was male futsal players in the age range 19-25 years who experienced ankle sprain from the polytechnic futsal team Dr. Rusdi Medan and the Set Setia futsal team that can take part in training programs at the Poltekkes Dr. Rusdi Medan during the research time. The research sample was chosen based on inclusion and exclusion criteria taken by consecutive sampling. The selected sample consists of 9 samples according to the calculation of the Pocock formula. The sample was treated with basic training therapy training with the addition of glute exercise. The study sample received the addition of glute exercise in basic isometric exercise therapy exercises, training techniques given muscle setting exercise and stabilization exercises with the addition of side planks with abduction leg downs, side planks with abduction leg ups, front planks with hip extensions and single-limb squats. The exercise is carried out for 8 weeks with a frequency of 2 times a week.

\section{How to Collect Data}

The research sample data is obtained by measuring ankle stability before training and after getting training. Ankle stability is measured by using a balance error scoring system (BESS).

Procedure for measuring ankle stability

Measurement with balance error scoring system (BESS), performed with 3 attitude conditions and 2 surface conditions, 3 attitude conditions namely double leg, single leg and tandem stances while 2 surface conditions are stable surface and unstable surface with total inspection position is 6 positions .

The examination is carried out for 20 seconds by means of the sample closing the eyes and both hands holding the waist, the amount of data obtained from counting the number of errors made by the sample. Errors assessed in the balance error scoring system include:

\begin{tabular}{|l|l|}
\hline \multicolumn{2}{|c|}{ Balance Error Scoring System (BESS) } \\
\hline 1 & Open eyes \\
\hline 2 & Lift hands from the hips \\
\hline 3 & hip flexion or abduction more than $30^{\circ}$ \\
\hline 4 & Lift the front legs or heels \\
\hline 5 & Touch non-weight-bearing feet to the floor \\
\hline 6 & Out of testing position (fall) \\
\hline 7 & Failed to return to the test position in more than 5 seconds \\
\hline
\end{tabular}

Respondent error value data for one test position is 0 (minimum) to 10 (maximum) errors. The assessment of the number of errors in this examination is to add up each error made during the test time. The BESS score obtained is the ankle stability value from the sample.

\section{Data Analysis}

The research sample data that has been obtained is analyzed using the SPSS program, the data analyzed are:

1. Characteristics of subjects to knowing the physical condition of the research subjects include: age, height, weight and duration of injury experienced by the sample whose data was taken before being given treatment.

2. Data normality test (ankle stability) with Shapiro Wilk test.

3. Data homogeneity test (ankle stability) with Levene's Test.

Data comparison test before and after treatment of ankle stability in the addition of glute exercise in basic exercise therapy with paired sample t-test.

\section{RESEARCH RESULTS AND DISCUSSION}

A. Description of subject characteristics

Descriptions of characteristics of research subjects in both groups are listed in Table 1

Table 1 Sampel Characteristics

\begin{tabular}{|c|c|}
\hline \multirow{2}{*}{ characteristics } & $(\mathrm{n}=9)$ \\
\cline { 2 - 2 } & Average \pm SB \\
\hline Age $($ th) & $21,78 \pm 1,98$ \\
\hline High $(\mathrm{cm})$ & $165,33 \pm 6,78$ \\
\hline Weight $(\mathrm{kg})$ & $66,67 \pm 4,69$ \\
\hline
\end{tabular}

Based on the analysis test Description of age ranged from 19-25 years with an average age $21.78 \pm 1.98$. Body weight descriptions ranged from $60-73 \mathrm{~kg}$ with mean weight $66.67 \pm 4.69$. Description of height ranged from $150-172 \mathrm{~cm}$ with mean height $165.33 \pm 6.78$. Looking at the $\mathrm{p}$ value $>0.05$ indicates that there are no differences in the characteristics of the study sample.

In addition to the characteristics of the subject above also discussed the duration of chronic ankle sprain injuries suffered by respondents, the duration of injury was calculated and grouped in a matter of months, as shown in Table 2 .

Table 2 Characteristics of Research Subjects Based on The duration of injury

\begin{tabular}{|c|c|c|c|}
\hline $\begin{array}{c}\text { Duration Of } \\
\text { Injury }\end{array}$ & $\mathrm{n}$ & $\%$ & Mean \\
\hline 1Month & 3 & 33,3 & \multirow{2}{*}{2,22} \\
\hline 2 Month & 2 & 22,2 & \\
\hline 3 Month & 3 & 33,3 & \\
\hline
\end{tabular}




\begin{tabular}{|c|c|c|c|}
\hline 4 Month & 1 & 11,1 & \\
\hline Total & 9 & 100 & \\
\hline
\end{tabular}

The duration of injury experienced by the study sample ranged from 1-4 months with a value of $p>0.05$ which means there is no significant difference between the distribution of samples between group I and group II.

B. Effects of the addition of glute exercise on basic exercise therapy basic training on improving ankle stability

Table 4 Effects of the addition of glute exercise on basic exercise therapy on improving ankle stability

\begin{tabular}{|c|c|c|c|c|}
\hline & \multicolumn{3}{|c|}{ Stability } & \\
\hline & Pre Test & Post Test & Difference & $p^{*}$ \\
\hline & 24,22 & $8,89 \pm 2,147$ & $15,22 \pm 2,635$ & 0,000 \\
$\pm 4,024$ & & & \\
\hline Ket. : $p^{*}$ & Paired Sample t test \\
\hline
\end{tabular}

Initial research the average value of ankle stability was $24.22 \pm 4.024$ errors (pre-exercise). After getting training in adding glute exercise in isometric exercise basic therapy, the mean value of ankle stability errors using BESS decreased to $8.89 \pm 2.147$ errors. With a value of $p=0,000$ because the value of $p<0.05$, it can be concluded that there is a significant difference in the mean value of ankle stability before treatment and after treatment.

The lack of strength in the hip abductor does not allow a person to start a hip strategy in time to withstand sudden external lateral disturbances / pressures. This situation can increase the risk of an ankle injury10. It can also occur in the opposite direction, with an injury to the ankle (ankle sprain and ankle isability) can cause weakness in the autogluteus muscles. This occurs because of changes in gluteus muscle activation after ankle sprain, changes in the workings of the gluteus muscle as a protective mechanism for the body after injury3.

Giving glute exercise to the abductor and hip ectensor, namely the gluteus madius and gluteus maximus muscles will help increase the strength of the gluteus muscle so that it has an impact on the improvement of lower extremity instability. This exercise will help improve postural control of lower extremity by improving existing muscle strength10.

The combination of glute exercise and isometric exercise basic therapy therapy will have an impact on two problem spots, namely the ankle that has a sprain and the hip area (gluteus) that has weakness. By giving these two methods the improvement of postural deficits, especially those related to stability disorders caused by ankle sprain, will be more quickly repaired.

\section{Addition of Glute Exercise to Basic Exercise Therapy Further Improves Ankle Stability of Chronic Sprain Ankle Patients}

The mean decreasing BESS error with glute exercise was $15.22 \pm 2.635$ with a value of $p=0.001(p<0.05)$, showing that improvement in ankle stability.

Impaired ankle stability results in slower activation of the ankle, knee, and hip muscles when compared to normal subjects. Under normal circumstances the work of the lower extremity muscle begins with the presence of anticipatory response to compensate for the delay in intrinsic muscle work, this will have an effect in preventing the occurrence of impaired balance in the lower extremity.[11]

Patients with impaired ankle stability have demonstrated different walking initiation strategies than normal people, this is related to changes in the supraspinal mechanism of motor control. The mechanism of the central nervous system plays a role in functional deficits related to ankle instability, so a comprehensive approach to rehabilitation that includes distal and proximal muscle function is needed.[12]

The statement above is in line with this study because the improvement in ankle stability is not only focused on the ankle (distal) but also provides training in the proximal muscles of the lower extremities, the gluteal muscle group.

On one-way hypothesis testing showed $\mathrm{p}<0.05$, it shows that the intervention in the group added glute exercise in isometric exercise therapy significantly better compared to the intervention in the isometric exercise therapy group in increasing the stability of ankle in cases of chronic ankle sprain.

\section{CONCLUSIONS AND SUGGESTIONS}

Based on the discussion above in this study it can be concluded that: The addition of glute exercise to basic exercise therapy further increases ankle stability in patients with chronic ankle sprain.

After doing all the research processes and by looking at the results of the study, suggestions that can be are:

1. Glute exercise is one of the training methods that can be used to improve ankle stability in patients with chronic ankle sprain. This refers to the improvement of ankle injuries. The treatment is not focused only on the ankle but also other parts that support ankle performance such as gluteal muscles.

2. Further research needs to be done on other training methods that can help improve ankle stability in patients with chronic ankle sprain in addition to the training methods in this study.

3. There is a need to measure ankle stability that has a better accuracy of the inspection results so that there is no difference in determining the value of ankle stability.

\section{REFERENCES}

[1] Bahr, R., Holme, I. 2003. Risk factor for sport injuriesa methodological approach. $\mathrm{Br} J$ Sports Med 2003;37:384-392 doi:10.1136/bjsm.37.5.384

[2] Sumartiningsih, S. 2012. Cedera Keseleo pada Pergelangan Kaki (Ankle Sprains). Jurnal Media Ilmu Keolahragaan Indonesia Vol 2. Edisi 1. Juli 2012. ISSN: 2088-6802

[3] Hertel, J. 2008. Sensorimotor Deficits with Ankle Sprains and Chronic Ankle Instability, Clinics in Sport Medicine. Virginia. Elsevier.

[4] Hertel, J. 2002. Functional Anatomy, Pathomechanics, and Pathophysiology of Lateral Ankle Instability. Journal of Athletic Training. 2002;37(4):364-375.

[5] Eric, E. and Dieter, R, 2001. A multi-station Proprioceptive Exercise Program In Patients With Ankle Instability. Med. Sci. Sports Exerc. Vol. 33, No. 12, 2001. 
[6] Page, P., Baton R., Clare C.F. 2010. Assessment and Treatment of Muscle Imbalance The Janda Approach. Los Angeles, CA. Human Kinetics.

[7] Mattacola, C.G. and Dwyer, M.K. 2002. Rehabilitation of the Ankle After Acute Sprain or Chronic Instabilit., Journal of Athletic Training. 2002;37(4):413-429.

[8] Kaminski, T.W., Heather, D.H. 2002. Factors Contributing to Chronic Ankle Instability : A Strength Perspective. Journal of Athletic Training. 37.4 (OctDec 2002): 394-405.

[9] Jong, K.K., Young-Eok K., et.al,. 2014. Which Treatment is More Effective For Fungtional Ankle Instability : Strengthening or Combined Muscle Strengthening and Proprioceptive Exercise. Journal of Athletic Training 2002;37(4):394-405.

[10] Presswood, L., John, C., Justin, W.L.K, and Chris, W. 2008. Gluteus Medius: Applied Anatomy,
Dysfunction, Assessment, and Progressive Strengthening. Strength and Conditioning Journal. Vol 3, No. 5 okt 2008.

[11] Deun, S.V, Filip F.S, Karel H.S., et.al,. 2007. Relationship of Chronic Ankle Instability to Muscle Activation Patterns During the Transition From Double-Leg to Single-Leg Stance. The American Journal of Sports Medicine, Vol. 35, No. 2. DOI: 10.1177/0363546506294470

[12] Feger, M.A., Luke D., et.al,. 2014. Lower Extremity Muscle Activation During Functional Exercises in Patients With and Without Chronic Ankle Instability. American Academy of Physical Medicine and Rehabilitation. Vol. 6, 602-611, July 2014. 